\title{
Ensaio sobre os fundamentos pedagógicos do método educativo de João Melchior Bosco (Dom Bosco)
}

\section{Essay on the pedagogical fundamentals of the educational method of John Melchior Bosco (Don Bosco)}

\section{Ensayo sobre los fundamentos pedagógicos del método educativo de Juan Melchior Bosco (Dom Bosco)}

Jorge Luís Mialhe ${ }^{1}$

Renato Kraide Soffner ${ }^{2}$

DOI: http://dx.doi.org/10.20435/serie-estudos.v26i57.1512

\begin{abstract}
Resumo: Este trabalho teve por objetivo o levantamento das bases pedagógicas do modelo educativo proposto por João Melchior Bosco, mais conhecido por Dom Bosco, sacerdote católico italiano do século XIX e fundador da Congregação Salesiana. Por meio de revisão de literatura de autores da própria Congregação e de fontes primárias (textos de Dom Bosco e de seus colaboradores), pudemos mapear a evolução dos princípios que sustentam o método educativo analisado e compará-lo ao que se chama hoje de Ciência da Educação, na tentativa de testar a condição de cientificidade do modelo salesiano. Concluímos que a iniciativa educacional de João Bosco não tem, originalmente, os fundamentos científicos da Pedagogia como conhecida hoje, mas foi revista por autores da Congregação Salesiana, com a finalidade de introduzir indicadores e critérios pedagógicos de modo a sistematizar e oficializar seu trabalho dentro dos princípios de uma Pedagogia formal. O que se chama hoje de "Pedagogia Salesiana" é, na verdade, o que os salesianos seguidores de Dom Bosco reconhecem como "Sistema Preventivo".
\end{abstract}

Palavras-chave: Dom Bosco; método educativo; ciência da educação.

Abstract: This work aimed to survey the pedagogical bases of the educational model proposed by John Melchior Bosco, better known as Don Bosco, 19th century Italian Catholic priest and founder of the Salesian Congregation. Through a literature review by authors from the Congregation itself and from primary sources (texts by Don Bosco and his collaborators), we were able to map the evolution

\footnotetext{
${ }^{1}$ Universidade Estadual Paulista "Júlio de Mesquita Filho" (UNESP), Rio Claro, São Paulo, Brasil.

${ }^{2}$ Centro Universitário Salesiano de São Paulo (UNISAL), Americana, São Paulo, Brasil.
} 
of the principles that support the analyzed educational method and compare it to what is today called Science of Education, in an attempt to test the scientific condition of the Salesian model. We conclude that John Bosco's educational initiative did not originally have the scientific foundations of Pedagogy as known today, but was revised by authors from the Salesian Congregation, with the purpose of introducing pedagogical indicators and criteria in order to systematize and officialize their work within principles of a formal pedagogy. What is called today "Salesian Pedagogy" is, in fact, what the Salesians followers of Don Bosco recognize as "Preventive System".

Keywords: Don Bosco; educational method; science of education.

Resumen: Este trabajo tuvo como objetivo sondear las bases pedagógicas del modelo educativo propuesto por Juan Melchior Bosco, más conocido como Don Bosco, sacerdote católico italiano del siglo XIX y fundador de la Congregación Salesiana. A través de una revisión bibliográfica de autores de la propia Congregación y de fuentes primarias (textos de Don Bosco y sus colaboradores), pudimos mapear la evolución de los principios que sustentan el método educativo analizado y compararlo con lo que hoy se llama Ciencia de la Educación, en un intento de poner a prueba la condición científica del modelo salesiano. Concluimos que la iniciativa educativa de Juan Bosco no tuvo originariamente los fundamentos científicos de la Pedagogía como se la conoce hoy, sino que fue revisada por autores de la Congregación Salesiana, con el propósito de introducir indicadores y criterios educativos para sistematizar y oficializar su trabajo dentro de los principios de una pedagogía formal. Lo que hoy se llama "Pedagogía Salesiana" es, de hecho, lo que los Salesianos seguidores de Don Bosco reconocen como "Sistema Preventivo".

Palabras clave: Don Bosco; método educativo; ciencia de la educación.

\section{INTRODUÇÃO}

O modelo educativo ${ }^{3}$ de João Melchior Bosco (1815-1888), sacerdote e santo da Igreja Católica conhecido como Dom Bosco, foi iniciado e pensado como ação educativa centrada nas características socioeconômicas do educando em situação

3 Diferenciaremos, aqui, um sistema educativo de um método educativo. O primeiro representa uma teoria pedagógica geral, enquanto o segundo é baseado em uma metodologia educacional. Nessa perspectiva, Dom Bosco estaria equivocado quando utilizou o termo "sistema" e não "método" na sua obra O sistema preventivo na educação da juventude, de 1877. Obviamente, esta é uma crítica contemporânea, na medida em que D. Bosco não tinha interesse, tendo em vista as suas circunstâncias históricas, de refletir sobre essa questão. Se utilizou o termo "sistema", foi por ter-Ihe parecido mais adequado, sem maiores preocupações epistemológicas. Pondera-se, assim, sobre a suposta cientificidade que o modelo educativo de D. Bosco poderia ter, em contraste com o que chamamos de Pedagogia, hoje. Nesse sentido, verifica-se um desacerto quando alguns autores se referem à existência de uma "Pedagogia Salesiana", que, neste artigo, será sempre grafada entre aspas. Observa-se, destarte, que, até a morte de D. Bosco, foi praticado um método educativo e, posteriormente, os autores salesianos têm-se esforçado para torná-lo um sistema. É indispensável reconhecer, contudo, que essa crítica não diminui em nada a relevância da obra de D. Bosco, pois trata-se de fomentar o debate acadêmico. 
de vulnerabilidade social - uma proposta pouco convencional para sua época, o chamado "Século da Pedagogia", e momento histórico da Revolução Industrial, que atingiu a Itália em pleno processo de reunificação. O processo de estabelecimento do capitalismo italiano, tanto como nos demais países europeus, a começar pela Inglaterra, foi cruel e desumano para as parcelas menos favorecidas da sociedade. Bosco conviveu com as visões iluministas e românticas de Rousseau (o papel do sentimento e do coração para com o educando), e com as visões mais científicas de Herbart, Pestalozzi e Froebel (a educação como processo).

A motivação e justificativa maior para este trabalho é a preocupação da Congregação Salesiana - fundada por D. Bosco em 18 de dezembro de 1859-com a questão da cientificidade do método educativo por ele proposto, visto que seu trabalho é de natureza educacional e formativa.

Buscamos, assim, apresentar uma revisão de literatura alicerçada nos próprios autores salesianos, conduzindo um levantamento histórico do desenvolvimento do pensamento educativo e pedagógico de que lançam mão para garantir o status científico para o modelo.

Iniciamos por uma contextualização do trabalho de D. Bosco, antes de uma discussão histórica e pedagógica sobre o assunto, a partir de registros históricos. Apresentamos, então, as iniciativas de ordem pedagógica de seus sucessores, que foi comparada com o que hoje se denomina Ciência da Educação. Pudemos, desta forma, verificar se D. Bosco constituiu, de fato, uma Pedagogia, no sentido apregoado na contemporaneidade. Este objetivo, como veremos, é de valor (e sempre foi) para a Congregação, que busca sistematizar a obra de D. Bosco dentro dos critérios da Ciência.

\section{O MÉTODO EDUCATIVO DE D. BOSCO: ORIGENS HISTÓRICAS E CONTEXTO EDUCACIONAL}

D. Bosco teve formação pedagógica num âmbito familiar e escolástico. Não fez parte de sua educação qualquer curso oficial de Pedagogia ou de formação de professores (PRELLEZO, 1997).

Segundo Stella (1996), uma conexão formativa mais significativa de D. Bosco com a Pedagogia científica e acadêmica de sua época não foi verificada formalmente, apenas contatos e relações de amizade com expoentes pedagógicos do período (Antonio Rosmini, Giovanni A. Rayneri, Giuseppe Allievo - representantes 
do movimento pedagógico piemontês da segunda metade do século XIX). O autor considera que, nesse contexto, dados e depoimentos sobre os contatos do fundador da Congregação Salesiana com os pedagogos mencionados e, em geral, com o contexto pedagógico de seu tempo, podem ajudar a identificar os aspectos mais ilustrativos e a compreender com mais facilidade os núcleos qualificados do pensamento de D. Bosco sobre educação e escola. Ao mesmo tempo, "[...] esses contatos revelam as características mais marcantes de seu método de educar jovens 'pobres e abandonados'” (STELLA, 1996, p. 8).

Também Vecchi e Prellezo (1988) afirmam que D. Bosco tem contato com a Pedagogia mais teórica por meio de autores de referência, mas tem vocação, inicialmente, para uma Pedagogia mais pragmática de ação educativa, desenvolvida no âmbito de sua vida de prestação de serviços a sujeitos em situação de risco social. Há um processo dialético entre sua prática educativa e a Pedagogia de bases científicas. Esta afirmação permeará todo o texto, constituindo-se em uma das premissas da argumentação aqui apresentada.

O que se chama hoje de "Pedagogia Salesiana" é, na verdade, o que os salesianos seguidores de D. Bosco reconhecem como "Sistema Preventivo" (SOFFNER; SANDRINI, 2012). Fundamenta-se no afeto, na razão e na religião, alicerces das ações pedagógicas, segundo D. Bosco. Pela instituição do Oratório, em 1841, uma organização que acolhia jovens em situação de risco social e pobreza oferecendo segurança, educação e formação religiosa, confirma-se a visão de Sandrini (2012) de que D. Bosco colocou no centro de seu "sistema" educativo a pessoa como valor absoluto. Tal dimensão foi sintetizada por Braido (1959) na sentença latina "Educatio quaerens intellectum, Quomodo fit educativo? Quid? Terminus a quo et ad quem?"4

O próprio D. Bosco descreveu seu método em sua obra O Sistema Preventivo na educação da juventude. Agasso, Agasso e Agasso Jr. (2015) identificam, neste texto, que o modelo salesiano "[...] consiste em fazer conhecer as normas e os regulamentos de um instituto e depois vigiar de tal modo que os jovens tenham continuamente sobre si olhar vigilante do diretor ou dos assistentes. [...] Este sistema se apoia todo na religião, na razão e na bondade" (AGASSO, AGASSO, AGASSO JR., 2015, p. 217, grifo nosso).

4 A educação é obrigatória, buscando a compreensão de: como pode ser educativo? O quê? O limite indicado por quem e para quem? (Tradução livre). 
Esses três pilares sobre os quais se sustenta o "Sistema Preventivo" foram descritos por Modesti (1975): a razão representa a racionalidade (guia de vida por meio das ideias e da verdade, ao lado da emoção e alheia às pressões físicas); a religião traz o sentido da vida no transcendente; o carinho é a característica principal da ação educativa de Bosco, como ele sempre enfatizará. Assim, ele defenderá um método educacional baseado na educação pelas ciências, artes, religião e virtudes sociais dos jovens (FIERRO TORRES, 1953).

O "Sistema Preventivo" é pautado pelos outros sistemas educativos, já identificados na época: preventivos ou repressivos, ${ }^{5}$ dependendo do papel do educador: num sistema preventivo este é guia junto ao educando, fornecendo conselhos e correções afetivas - a amorevolezza, ou carinho, ou afeto (SCARAMUSSA, 1984; AUFFRAY, 1925).

Já num sistema repressivo, conforme Colli (1982), as regras são valorizadas sobremaneira, vigiando-se e punindo-se os eventuais transgressores. O próprio D. Bosco defende os "sistemas preventivos", o que nos faz entender o porquê do nome escolhido para o seu (BOSCO, 1877).

De acordo com Lenti (2013), só depois de 1877 D. Bosco usou o termo preventivo para referir-se ao seu método. Parece que ele adotou o termo para dar ao seu sistema um marco teórico, ou seja, classificá-lo na história da pedagogia (LENTI, 2013, p. 95).

Assim, em 1880, o método já era vivido através do Oratório e conhecido por seus seguidores, sendo considerado como uma criação da experiência educativa de D. Bosco e do seu compromisso de colocar a vida a serviço da juventude (LENTI, 2012, p. 96).

\section{O PAPEL HISTÓRICO E PEDAGÓGICO DE D. BOSCO NA EDUCAÇÃO}

Os historiadores da educação fazem referência à pessoa de D. Bosco como educador relevante na Itália do século XIX, período denominado na historiografia peninsular como Risorgimento. Nesse contexto, Manacorda (2010) reconhece a importância de D. Bosco como educador para a época:

5 Segundo Corallo (1979), Dupanloup já falava de três sistemas: o repressivo, o preventivo e o diretivo. A inovação de $\mathrm{D}$. Bosco é descartar a possibilidade do modelo repressivo na educação de jovens e seguir São Paulo no "tratamento do mal com o bem" (CORALLO, 1979, p. 16). Analisa o que o jovem é, para determinar o que deve ser (tratamento axiológico da questão da educação). 
Como um dos muitos testemunhos da perene vitalidade da tradição católica, não podemos deixar de lembrar, nesse período, pelo menos a obra educativa de Dom Bosco, que, iniciada modestamente, impôs, através da congregação salesiana, a presença católica no panorama educativo do mundo moderno. Sua obra destaca-se tanto pela reflexão pedagógica, como pela iniciativa da educação popular profissional. (MANACORDA, 2010, p. 356).

Acredita, esse historiador romano, que o sucesso da práxis pedagógica de D. Bosco é um misto de antigo e de novo, ou seja, "[...] de intransigência teológica e de bondade conjugada com a severidade religiosa" (MANCORDA, 2010, p. 356).

Por seu turno, Cambi (1999) não cita o sacerdote no capítulo sobre a Pedagogia italiana do Risorgimento. Porém, ao tratar dos pedagogos e educadores católicos do século XX, o autor resgata a contribuição anterior de D. Bosco: "Já no curso do século XIX, uma excepcional figura de educador, D. Bosco, tinha aberto novas perspectivas à educação cristã, dedicando-se ao cuidado das crianças pobres, abandonadas e vadias" (CAMBI, 1999, p. 567).

Para Braido (2004), autor salesiano de referência, D. Bosco não inventou um novo sistema pedagógico, nem um método original e revolucionário. Declara que não se fala de D. Bosco como de Montessori ou Decroly. Nem mesmo como de teóricos da Educação tal qual Comênio, Rousseau, Pestalozzi ou Froebel. Embora alguns autores contemporâneos considerem D. Bosco como fundador de uma Pedagogia própria, ele mesmo nunca afirmou ter um modelo científico e formal (BRAIDO, 2004).

Prellezo (1997) afirma que D. Felipe Rinaldi, terceiro sucessor de D. Bosco à testa da Congregação Salesiana, já em 1926 lamentava a falta de um manual ou texto de "Pedagogia Salesiana", para que "Dom Bosco pudesse ser plenamente compreendido" (PRELEZZO, 1997, p. 7).

Por ser ars artium ${ }^{6}$ da educação, Prellezo considera ser impossível caracterizar uma real Pedagogia a partir e somente dos textos do próprio D. Bosco. Por isso Braido (1958) discute as relações entre o "João Bosco educador" e o "João Bosco pedagogista"7. O primeiro, de acordo com o autor, é o educador prático e

6 Arte das artes (Tradução livre). Significa lógica, uma vez que qualquer outro exercício da mente humana depende de raciocínio lógico.

7 Conforme Silva (1938), o termo pedagogista foi muito utilizado no século XIX e na primeira metade do Século XX, ao referir-se ao profissional teórico da educação, responsável pela pesquisa educacional, enquanto o termo pedagogo sempre trouxe a conotação mais aplicada e 
de atendimento à comunidade em que se insere, na esfera dos meios; o segundo, o teórico que reflete a educação como processo e guiada pelos fins.

Assim, se a Pedagogia é aceita como ciência da educação e como sistema teórico, qual seria a contribuição de Dom Bosco para a História da Pedagogia? O mesmo autor refere-se a Gentile ${ }^{8}$ em sua crítica sobre "as obras que em vão se procurariam" para justificar a cientificidade das obras de D. Bosco e de outros autores da época - embora o reconheça como "grande educador" (BRAIDO, 1958, p. 315).

Para Fascie (1927),

Dom Bosco não foi teórico da Pedagogia [...] faltam razões e documentos para se poder afirmar que ele se tenha dedicado intencionalmente e ex-professo ao estudo de problemas especulativos da Pedagogia técnica e tenha de qualquer modo pretendido passar por um cientista em Pedagogia. (FASCIE, 1927, p. 19-21).

O próprio D. Bosco reconhece que não identifica seu suposto método próprio, como queriam alguns, e que teria sempre agido de acordo com as circunstâncias e as inspirações divinas. Tinha, portanto, mente prática e bom senso, sendo pouco ligado a abstrações, teorias e intelectualidades (BRAIDO, 1958). O que sugere que não quis se acorrentar a um sistema rígido e estereotipado que Ihe tolhesse a liberdade e a agilidade de movimentos. Mas não caminhou ao acaso e acabou por conceber um sistema próprio - a que, como visto, chamou de Preventivo.

Assim, conforme Fascie (1927), sai D. Bosco da Pedagogia teórica (chamada na época de especulativa) para o campo prático da "arte educativa" e da "obra do educador" - onde foi "verdadeiro mestre" e imprimiu seu cunho característico. Esse autor acredita que o "Sistema Preventivo" seja o fundo doutrinal da atividade prática do educador aqui estudado (FASCIE, 1927, p. 22).

Tal visão é compartilhada por outro historiador de D. Bosco, Ceria (1937). Este não acredita que o "Sistema Preventivo" seja método novo, pois D. Bosco já sabia ser conhecido, mas atuou de forma original para uma aproximação com suas próprias ideias. Também Ferreira (2013, p. 11) confirma que "É sabido que

de prática docente desse profissional. Note-se que é este o enfoque dado pela atual legislação educacional no Brasil.

8 GENTILE, Giovanni. Giornale Critico della Filosofia Italiana. [S.I: s.n.], 1926. 
Dom Bosco não inventou o Sistema Preventivo em nenhuma das versões mais conhecidas de seu tempo - pastoral, educativa, correcional, social, demográfica, política". Mas certamente o enriqueceu e inovou, na variação das atitudes, dos meios e dos modos de relação, graças a processos educativos, intencionais ou não, que marcaram estavelmente sua personalidade, enriquecendo-a progressivamente de traços característicos.

O sistema de D. Bosco se desenvolveu como um sistema de educação e de Pedagogia integradas não só no campo natural, mas também no sobrenatural. É fruto de uma evolução prática e refletida que vai desde o início do Oratório até algumas cartas dos anos 1884 e 1885 (BRAIDO, 1958).

Scaramussa (2013) afirma que D. Bosco não era teórico da educação, mas tinha sensibilidade para perceber as necessidades das pessoas e as mudanças na sociedade de seu tempo. Sua prática tinha caráter sistemático, esboçado no seu "Sistema Preventivo". Deu arranjo próprio à mentalidade pedagógica de seu tempo, em termos de práticas educativas. O autor comenta que toda teoria da educação busca atender às necessidades educativas e aos problemas de um determinado tempo - as finalidades da educação, o alcance e sua pertinência sociocultural - consolidados como sistematização de ideias e metodologias de aprendizagem: o sujeito, a sociedade, os conteúdos e as interações pedagógicas. Afirma que, como em Paulo Freire, D. Bosco buscava a autonomia, a autenticidade e a responsabilidade da juventude, com educação para o senso crítico diante da vida pessoal, do ambiente e da sociedade em geral, formando sua própria cultura, em diálogo com o educador (SCARAMUSSA, 2013).

Casotti (1940) também defende a visão de que D. Bosco não era - e nem queria ser - um estudioso. Acredita que poderia ter sido, pois tinha todas as condições para tal, mas sentia que sua vocação era outra - não a de teólogo, ou filósofo, ou mesmo pedagogista, mas educador e fundador. Sentia-se inclinado a agir, e não a escrever.

Afirma o quarto sucessor de D. Bosco na direção da Congregação Salesiana, Dom Pietro Ricaldone (1953, p. 53): “Por 'sistema educativo de Dom Bosco' devemos entender as ideias, os princípios e os meios que moveram, regularam e realizaram a sua acção (sic) educativa". No entanto D'Arcais (1951) traz uma visão que defende uma Pedagogia de D. Bosco, pois este teria meditado sobre o fato educativo, o que Ihe confere seriedade histórica, teórica e original. E Burg (1940) 
alerta para o fato de que o "Sistema Preventivo" é apenas parte do método educativo de D. Bosco, algo mais complexo para ser limitado a esse simples componente.

Finalmente, Fierro Torres (1953) constrói sobre a pauta do método preventivo de D. Bosco todo um quadro sistemático de Pedagogia geral e especial, enquanto Modesti (1975) pondera que os próprios escritos pedagógicos de D. Bosco se constituem em prova de sua Pedagogia, já que, mesmo acatando as críticas daqueles que não o consideravam um "pedagogista", tais documentos têm valor pedagógico de fato: os regulamentos, a própria descrição do "Sistema Preventivo", as memórias do Oratório, o relato de seus sonhos, entre outros. Também Ricaldone (apud MODESTI, 1975) avalia que, mesmo tendo o próprio D. Bosco evitado a "esclerose" dos tratados pedagógicos formais para não contaminar sua obra, que qualifica como eficaz e produtora de resultados tangíveis, seria impossível que tal esforço não gerasse indicadores e direcionamentos de fundo pedagógico. Afirma ainda que a coerência e o ineditismo de seu trabalho são suficientes para embasá-lo com conceitos de origem educativa e pedagógica.

Silva (1938) viu em D. Bosco uma vocação para pedagogista ou teórico da educação. Em oposição, Braido (2004) é claro ao afirmar que D. Bosco não deixou uma exposição sistemática de reflexão pedagógica de sua prática, embora os documentos de sua autoria sirvam de base educativa, mas preocupou-se em buscar uma visão teórico-prática dos fins da educação, sem sistematizar os meios para isso. Para Prellezo (1997), não existem indícios de que D. Bosco tenha tido contato com a Pedagogia científica de seu tempo, embora seus primeiros seguidores tenham se preocupado com tal atualização. Como já mencionado, esse autor acredita que Bosco tenha buscado, de fato, uma Pedagogia do carinho, mais arte que ciência.

Segundo Santos (2000), o educador D. Bosco tinha espírito eminentemente prático, e é lembrado não por ser um teórico da educação, mas por sua visão pragmática e experimental do ato de educar. Acredita que não pretendeu formular um sistema de bases pedagógicas e científicas, mas que parece ser possível, mesmo assim, extrair uma síntese de ideias, princípios e métodos de bases científicas, teológicas, filosóficas e experimentais de sua obra. Para Prellezo (1997), suas orientações educativas, oriundas de reflexões pessoais baseadas em seu cotidiano de educador, têm sempre o caráter de ação concreta, de práxis, e lembram um conjunto de modus operandi indicados para situações específicas, acessíveis por qualquer agente educativo, mas sem preocupações científicas. 
Para Nanni (1989), o "Sistema Preventivo" é um modelo maior de sistema educativo, mas sem se constituir, necessariamente, num estatuto de ciência de educação. No entanto Cimatti (1939), em seu tempo, já apresentava as divisões da Pedagogia sistemática da época: o conceito de educação, os fatores educativos, os meios gerais de educação e os princípios diretivos ou método educativo. E acreditava que todos esses elementos se encontram na teoria e prática de D. Bosco.

Damas (2004) enxerga, no modelo educativo de D. Bosco, uma concepção antropológica, pois considera o ser humano nos aspectos racional, emocional, corporal e espiritual. Acredita que prática educativa salesiana assenta-se sobre o tripé razão-espiritualidade-amor, que, para ele, refere-se a questões contemporâneas, em que o professor-educador assume, em relação ao educando, um papel de mediador da construção do conhecimento e da afirmação de si mesmo no mundo, gerando responsabilidade ética, capacidade de justiça e solidariedade.

Ferreira (2008) afirma que D. Bosco apresentou mais uma narrativa de seu modelo educativo do que conceitos e normas de uma Pedagogia formal, mostrando que, para ele, a educação é formação integral da pessoa, em suas várias dimensões, inclusive a transcendente, de cunho religioso, aspecto este impossível de ser separado de suas ideias, dada a origem e a prática sacerdotal de Bosco. Há aqui o senso do e-ducere, do trazer para fora as potencialidades de cada um a fim de formá-las à luz de uma doutrina pedagógica e de sociedade. Ferreira ainda alerta para que se considere, nas palavras de D. Bosco, o potencial político da educação, como depois apontado por Paulo Freire. Também afirma que Bosco se preocupa com as relações humanas, e não com teorias psicológicas ou pedagógicas formais, ou com aspectos didáticos específicos, ou mesmo epistemológicos. Coloca que o sacerdote salesiano descarta a submissão do logos à techné ${ }^{9}$, mais especificamente a relação de conflito entre eles, pois acredita na complementaridade entre educar para a razão e para a religião, como também no educar para o trabalho.

A revisão de literatura nos permite considerar o modelo educativo de D. Bosco um sistema prático na essência, com testemunhos e elogios pelo arrojo e inovação (BRAIDO, 1958). Mas é necessário que o analisemos do ponto de vista de sua participação efetiva na História da Educação (ou da Pedagogia), em busca de uma reflexão teórica sobre sua prática e, portanto, de sua práxis.

\footnotetext{
9 Palavra ao ofício; discurso à arte.
} 
Para Caviglia (1987),

[...] o sistema de Dom Bosco não contempla expressamente um método didático, uma seriação de estudos, como a Conduite des Écoles de La Salle ou a Ratio Studiorum da Companhia de Jesus". [Todavia] tem, e é natural, uma relação também com o modo de ensinar, qualquer que seja o programa de uma escola. (CAVIGLIA, 1987, p. 29).

Acredita este autor que modelo educativo salesiano afeta a didática positivamente, pois preconiza a abnegação do mestre com a correspondência recíproca do aluno. Isso confere ao modelo solidez e profundidade suficientes para ser caracterizado como de interesse para a Pedagogia contemporânea. Embora Casasanta (1934) tenha criticado os historiadores da educação pela omissão do nome de D. Bosco na lista dos grandes pedagogos e educadores da história, reconheceu que, apesar da ausência de bases teóricas, o trabalho de Bosco tem seu mérito como conjunto de práticas educativas e de busca pela construção de um bom cidadão e cristão. A isso Prellezo (1997) chamou de "Pedagogia da Confiança", ou "Pedagogia do Carinho".

Stella (1996, p. 7) questiona-se: "Que lugar ocupa Dom Bosco na História da Educação?". A pergunta não tem respostas homogêneas, mas D. Bosco é visto, por muitos estudiosos, como um grande educador do século XIX, até mesmo considerado o "Pestalozzi católico".

No entanto existe um relativo consenso, entre autores da área da educação, em afirmar uma ausência inicial de cientificidade no trabalho educativo de D. Bosco. Assim, é necessário que apresentemos algumas propostas de autores salesianos que buscaram amenizar essa situação de ausência na "Pedagogia Salesiana".

\section{DA PEDAGOGIA COMO CIÊNCIA DA EDUCAÇÃO: O TRABALHO PIONEIRO DE CARLOS LEÔNCIO DA SILVA}

O sacerdote salesiano Carlos Leôncio da Silva foi autor e pesquisador de destaque e pioneiro nas questões da cientificidade e da metodologia da educação e, portanto, da Pedagogia. Seu livro Pedagogia: Manual Teórico-Prático para Uso dos Educadores, de 1938, é considerado um texto clássico da primeira metade do século XX, tanto no Brasil como na Europa (SILVA, 1938; BUENO, 1992; CASTILHO, 2007). Dotado de vocação para o que se chamava, na época, de pedagogista (teórico da educação), Silva assumiu uma orientação espiritualista-cristã, 
diversamente de John Dewey, Anísio Teixeira e Lourenço Filho, representantes de uma corrente naturalista-sociológica. Diferia, também, do funcionalismo de Claparède, bem como da visão sociológica de Durkheim.

Para o autor do Manual, a educação é o conjunto de ações com o fim de estimular, desenvolver, guiar e fazer chegar à sua plena eficiência todas as potências e faculdades do ser humano, para desenvolver e formar o educando, numa clara relação com os conceitos de Bildung e Paideia ${ }^{10}$. Já a Pedagogia, para Silva, é o conjunto de conhecimentos e ações cientificamente organizados e seriados, tendo, como objeto material, o homem e, como objeto formal, a sua educação (educere - extrair, trazer para fora, educare - cuidar) e instrução (instruere - acumular, dispor, recolher e infiltrar no ânimo noções e conhecimentos necessários e úteis à vida). Sendo o objeto da Pedagogia a educabilidade, ela é vista de forma independente das suas demais ciências auxiliares (como a psicologia, a filosofia, a sociologia e a história).

Pode-se afirmar, portanto, que existe uma nítida diferença entre a Pedagogia, ciência (especulativa) e a arte de educar (normativa, mais prática, técnica, metodológica). A arte empírica realiza a ciência pedagógica, complementando-a (práxis). A Pedagogia é ciência, não no sentido moderno e positivo que busca as leis dos fatos de que se ocupa, mas no sentido de ciência especulativa que indaga o porquê ou a causa das coisas (BUENO, 1992).

A Pedagogia é, assim, a ciência ou teoria da educação, enquanto a educação é a prática do educar, a ação educativa - seja aquela que se desenvolve na família, na escola ou na sociedade em geral:

Por ciência da educação entendemos, não só a prática e a arte educativa, e nem só o conhecimento empírico, mas o conhecimento adequado, completo, exaustivo do problema educativo, capaz de iluminar racionalmente e prática da educação do homem, segundo as leis físicas da natureza, segundo a moral natural e segundo a mensagem cristã da fé, em uma palavra, segundo todo o homem histórico atual. (SILVA, 1938 apud BUENO, 1992, p. 70).

\footnotetext{
${ }^{10}$ Formação, educação entendida como desenvolvimento integral e espiritual através da cultura. Conforme Werner Jaeger (1995), "Só a este tipo de educação se pode aplicar com propriedade a palavra formação tal como a usou Platão pela primeira vez em sentido metafórico, aplicando-a à ação educadora. A palavra alemã Bildung (formação, configuração) é a que designa de modo mais intuitivo a essência da educação no sentido grego e platônico".
} 
Para Silva (1938 apud BUENO, 1992), as divisões da Pedagogia seriam: a) o educando (o aluno); b) sua educação (física, intelectual, moral e social); c) o educador (o pedagogo); d) os sistemas e ambientes de educação (natureza do aluno, fins da educação, meios, modo de aplicação: a escola). Afirma ainda que a Ciência da Educação deve conter os seguintes gêneros de conhecimento:

Positivo-descritivo: relativo a todos os fatores sensíveis, materiais e positivos do fato da educação (sujeito por educar-se, educador, meios de educação, condições sociais da educação, conhecidos por um conjunto de leis que as ciências positivas podem fornecer);

Especulativo: concernente a todos os princípios ontológicos e morais que dão razão aos fatores da educação e que são deduzidos dos respectivos princípios filosóficos metafísicos e morais;

Teológico: relacionado à contribuição ou às exigências metafísicas e morais que a Revelação apresenta e acrescenta ao problema educativo natural. (SILVA, 1938 apud BUENO, 1992, p. 45).

O fim da ciência pedagógica será, então, de acordo com Silva (1938 apud BUENO, 1992), recolher elementos dessa formação em síntese lógica racional, para que ocorra com consciência e competência requeridas pela própria natureza do problema. Aqui o emprego das ciências auxiliares pode ser inserido, mas a Pedagogia deve permanecer intocável em sua exclusividade característica, para facilitar a clareza dos conceitos, dos princípios e das aplicações práticas da própria educação, evitando o que ele chama de "nebulosidade" da linguagem pedagógica. Desse modo, Silva afirma que o estudo científico da Pedagogia deve compreender o conhecimento do fato educativo e as causas do seu devir.

Silva (1938 apud BUENO, 1992) divide a Pedagogia em Geral Especulativa em oposição à Especial Prática (ou normativa - a arte da educação). Sua definição da própria Pedagogia tem relação com a etimologia do termo (paidós + agein), ou seja, a educação da criança, como praticada na Grécia e em Roma Antigas. Assim, para esse estudioso, a Educação é a prática do educar, a ação educativa, desenvolvida na família, na escola, na comunidade, na sociedade.

Já a Pedagogia é definida como a Ciência ou Teoria da Educação. O fim da Pedagogia é, então, a formação do homem, em toda a sua vida. Por isso, deve reunir todos os elementos dessa formação em síntese lógica e racional, a fim de executá-la da forma apropriada e limitada pela ação educativa. Também para 
Bueno (1992), a Pedagogia especulativa preenche todos os requisitos da Ciência, pois é conhecimento rigoroso, metódico e sistemático da realidade, que busca verdades válidas para todos os casos, em qualquer tempo ou qualquer lugar.

Um elemento fundamental na definição de uma Ciência é seu objeto. Na Pedagogia, existe o objeto material, vale dizer, o conjunto de fatores físicos e morais, nos quais se verifica o fato educativo e se encontra uma relação de educabilidade (SILVA apud BUENO, 1992). É a própria educação e o estudo profundo de suas causas - o homem em seu devir, em seu ambiente, com seu educador e seus meios de educação. Existe, ainda, de acordo com o autor, o objeto formal, a saber, a educabilidade do homem, no âmbito da Ciência da Educação, exclusividade da Pedagogia em relação às outras ciências. E, finalmente, há também a metodologia e o método da Pedagogia: o fato e os problemas educativos formulados e precisados segundo os princípios e dados das ciências auxiliares, o estudo à luz dos princípios pedagógicos experimentais da educação - normas e procedimentos práticos da ação educativa. Consideram-se, assim, a estrutura, o conteúdo, as finalidades e o educador aplicando a ciência do pedagogista (pedagogo).

Percebe-se, assim, que a conceituação de Silva de Pedagogia como Ciência é relativamente atual e possibilita que se pense o método de Bosco como científico, respeitando as limitações colocadas pelo próprio Bosco, que buscava a prática educativa.

\section{PROPOSTAS PEDAGÓGICAS DE OUTROS AUTORES SALESIANOS: A TEORIZAÇÃO DO MODELO EDUCATIVO DE D. BOSCO}

Além da proposta pioneira de Silva, outras foram apresentadas por seus sucessores na Congregação Salesiana e revelam, como será visto adiante, fundamentação teórica mais sólida do que aquela iniciada pelo fundador, servindo, portanto, de ponto de comparação com a proposta de Bosco. Esses sucessores foram teóricos e pedagogistas de influência na composição do modelo educativo que representa os Salesianos de Dom Bosco (SDB). São autores formados pelas unidades pedagógicas salesianas, em especial o Pontifício Ateneu Salesiano (PAS), estabelecido em Turim em 1940 e transferido em 1965 para Roma. Em 1973, o PAS foi elevado à condição de Universidade Pontifícia Salesiana (UPS).

Segundo Prellezo (1997), os precursores da denominada "Pedagogia Salesiana" formam uma linha do tempo que se inicia com D. Bosco e vai até meados 
do século XX. Partindo da orientação de D. Pietro Ricaldone (antecedido pelos salesianos D. Lemoyne e D. Rinaldi, que já incentivavam a teorização do modelo educativo de D. Bosco), para que se empreenda um "studio della Pedagogia in modo scientifico", o PAS assume a coordenação de esforços. Entre os primeiros autores que compõem o estudo, estão Francesco Cerruti (1883) e Bartolomeo Fascie (1927). É deste último a obra Del metodo educativo di Don Bosco.

No entanto o trabalho de outro sacerdote salesiano, Rodolfo Fierro Torres, parece ser de interesse maior. O seu texto, de 1953, é considerado, tanto quanto a obra de Silva, um marco na discussão sobre a cientificidade da "Pedagogia Salesiana". Segundo esse autor, D. Bosco não escreveu nenhum tratado de Metodologia e nem de Pedagogia sistemática. Mas em seus regulamentos, cartas e discursos encontra-se um modelo educativo "[...] eloquente e preciso. [Um] sistema de educação salesiano baseado no amor" (FIERRO TORRES, 1953, p. 284), em que o educador encontra subsídios para se entregar inteiramente à tarefa a ele proposta. Nesse sistema, protagonismo e respeito são devidos ao educando, dentro de uma filosofia da razão-religião-carinho, que compõe (como visto anteriormente) o "Sistema Preventivo" de D. Bosco.

A educação, em Fierro Torres (1953), é a formação integral do homem, entendida como o desenvolvimento harmônico e ao mais alto grau possível de todas as faculdades e potencialidades humanas. O autor fundamenta-se no quadrilátero das causas de Aristóteles: material, formal, eficiente e final. ${ }^{11}$ Para Fierro Torres, a Filosofia como "Ciência dos Fins" define as metas. E a Psicologia trabalha o conhecimento dos objetos e do sujeito, bem como os meios relacionados aos procedimentos.

O texto de Fierro Torres (1953) se divide em: a) missão do educador e do educando, que compreende a finalidade da educação, seu campo de operações e o empenho do educador; b) a criança e sua educabilidade, envolvendo a educação anatômica, fisiológica, psicológica e espiritual; c) Educação Física, abrangendo os jogos e passeios, o atletismo e a ginástica; d) educação intelectual, que engloba os sentidos, a inteligência, a linguagem, o ensino de algumas ciências, a religião e a filosofia; e)

\footnotetext{
11 “No caso de uma estátua, a causa material é a matéria da qual ela é feita (mármore); a causa formal é a figura que ela representa (Apolo); a causa eficiente é o escultor (Fidias); a causa final é o objetivo visado pelo escultor (glória). No domínio científico, sobretudo a partir da revolução galileana, quando se fala de causa, refere-se apenas à causa eficiente". (JUPIASSU; MARCONDES, 1996, p. 40).
} 
educação moral, que envolve a vontade, os defeitos naturais, disciplina, castigos e repreensões, prêmios, educação social, autoridade e liberdade; f) metodologia e didática, resultado da formação do educador; e, por fim, g) a organização escolar.

Fierro Torres (1953) considera que existem dois grandes fatores da educação: o educador e o educando. O primeiro promove e o segundo coopera, numa relação de colaboração. Também considera o papel da família, da sociedade civil e da Igreja na educação do jovem. Considera, ainda, que o desenvolvimento e o aperfeiçoamento, com normalidade e harmonia, devem estar entre os objetivos da educação.

Partindo da proposta de entendimento profundo do educando e antes mesmo da proposição de ações educativas, Fierro Torres (1953) defende o emprego de experimentação psicológica no estudo educacional, bem como os métodos ativos de Dewey e Decroly. Considera a personalidade e o temperamento do aluno como variável de personalização do processo educativo, convergindo para o respeito ao sujeito, como indicado por D. Bosco.

Na seção sobre a Educação Intelectual, Fierro Torres (1953) apresenta ampla discussão didática e epistemológica dos processos de ensinar e de aprender, a partir do que se conhecia na época. Já os aspectos de salesianidade da obra dizem respeito às escolas profissionais, aos jovens em situação de risco social e ao Oratório Festivo. Finalmente, e como esperado para a época, há discussões, no final da obra, sobre disciplina, moral e civismo, castigos e repreensões, prêmios e organização escolar. Nessas discussões, o autor dá detalhes sobre os papéis de diretores e assistentes, considerados pelos salesianos como sujeitos fundamentais para a estrutura de trabalho da Congregação.

\section{PEDAGOGIA COMO CIÊNCIA DA EDUCAÇÃO: ELABORAÇÕES CONTEMPORÂNEAS PARA A CONTRAPOSIÇÃO E SISTEMATIZAÇÃO DAS PROPOSTAS APRESENTADAS COM O MÉTODO DE D. BOSCO}

Com o objetivo de estabelecer bases epistemológicas para a análise e o entendimento do que foi idealizado pelos autores até aqui considerados e, em especial, D. Bosco, discutiremos, agora, a questão da Pedagogia e da educação em suas associações com outras ciências.

Propomos, como conceito de educação, o estudo do processo que se dá pela ciência, ou seja, um complexo de regras que surgem de princípios e pela Arte Pedagógica, entendida como a aplicação de normas sugeridas pela prática e 
transmitidas pela tradição docente. Nesse sentido, é importante questionar: para que serve a educação (indagação da filosofia)? Como se faz educação (objeto da Pedagogia, da metodologia)? Quais são os fundamentos psicopedagógicos da educação (focada nas teorias de aprendizagem)? Quais são as teorias de ensino (didática - bases para se atingir objetivos instrucionais orientados pelos serviços mais gerais de aprendizagem)?

Paulo Freire ${ }^{12}$, entre outros educadores, reconhece o papel das demais ciências e disciplinas auxiliares em suas atividades e reflexões, já que a Pedagogia estuda a educação como fenômeno complexo e multirreferencial, a partir dos conhecimentos de outras ciências que podem colaborar nesse entendimento. No entanto isso não se apresenta como consenso na definição de Pedagogia.

Para Estrela (2018), o real objeto pedagógico é o ato de observar e de descrever fenômenos pedagógicos por meio de vários métodos e instrumentos de pesquisa que precisam ser próprios, já que o psicólogo, por exemplo, não faz Pedagogia, apenas aplica conceitos e métodos de sua ciência na educação. São irredutíveis pedagógicos, como objetos de estudo e reflexão, o aluno em situação de ensino e aprendizagem (e não enquanto criança, como na Psicologia), o saber, o professor e a escola.

Mazzotti (1996) define Pedagogia como ciência da prática, a ciência de um objeto inconcluso que se modifica pela ação. Não é uma tecnologia, mas uma reflexão sistemática sobre uma técnica particular, que é a educação. Para Pourtois e Desmet (1999), educamos o indivíduo (ou homem social) no ato educativo, portador de um conjunto de objetivos de fundo cultural e ideológico.

Diante das definições e conceitos apresentados, podemos inferir que a Pedagogia é a ciência que tem, como objetos específicos de estudo, o ato e o modo de educar. Cabe, então, refletir sobre sua relação com as outras Ciências da Educação e estabelecer sua responsabilidade no estudo de seus objetos específicos. A Pedagogia e a educação, relacionadas como parte e todo, respectivamente. 


\section{CONSIDERAÇÕES FINAIS: UMA "PEDAGOGIA SALESIANA"?}

Tendo utilizado como referenciais de análise a obra de D. Bosco complementada pelo conjunto intelectual e pedagógico de autores salesianos, e continuando a proposta deste trabalho pela comparação daquele levantamento com outras definições da Pedagogia, a partir de agora, poderemos considerar a cientificidade do método de D. Bosco.

Vimos que as exigências epistemológicas da Pedagogia, enquanto ciência, demandam que haja seus próprios fundamentos, objetos, objetivos, sujeitos (educador e educando) e métodos, para que se possa declarar a existência de um estatuto científico. Dirigida à formação do homem, a Pedagogia precisa de uma concepção científica desse homem. Mas não pode limitar-se à reflexão filosófica e teológica. A fim de se dirigir ao homem como sujeito concreto da educação, não se pode prescindir do conhecimento pedagógico ausente da sistematização e formalização características de uma ciência.

Nossa pesquisa nos leva a crer que o método de D. Bosco tem seu valor histórico e educacional, sem dúvida. É fato reconhecido desde seu tempo de vida, de acordo com os autores que a ele se referiram. No entanto, para se constituir em uma Pedagogia, carece de bases científicas que o classifiquem como tal. Essa suposta desvantagem acadêmica foi relativizada pela obra de seus sucessores, como Silva (1938) e Fierro Torres (1953), que desenharam propostas científicas e pedagógicas de base para o modelo de educação salesiano.

Como diz o mote do próprio D. Bosco, Da mihi animas, caetera tolle: "Daime as almas, leve o resto". Eis a essência de seu método, ainda que carente de um status científico.

\section{REFERÊNCIAS}

AGASSO, Domenico; AGASSO, Renzo; AGASSO JR., Domenico. Dom Bosco, uma história para todos os tempos. Brasília, DF: EDB, 2015.

AUfFrAY, A. Metodo educativo del Ven. Giovanni Bosco. Turim: Società Editrice Internazionale, 1925.

BOSCO, Giovanni. I/ sistema preventivo nella educazione della gioventù. Torino: Tipografia Salesiana, 1877. p. 3-13. 
BRAIDO, Pietro. Método educativo de São João Bosco. Lisboa: Editora Salesiana, 1958.

BRAIDO, Pietro. Prevenir, não reprimir: o sistema educativo de Dom Bosco. São Paulo: Editora Salesiana, 2004.

BRAIDO, Pietro (Org.). Educare: Sommario di scienze pedagogiche. Roma: Pontificio Ateneo Salesiano, 1959.

BRAIDO, Pietro. Prevenir, não reprimir: o sistema educativo de Dom Bosco. Tradução de Jacy Cogo. São Paulo: Editora Salesiana, 2004.

BUENO, Belmira Oliveira. Epistemologia da pedagogia: um estudo sobre as obras de Carlos Leôncio da Silva. São Paulo: Editora Salesiana Dom Bosco, 1992.

BURG, C. Don Bosco und seine pädagogik. Bigge: Josefs-Druckerei, 1940.

CAMBI, Franco. História da pedagogia. Tradução de Álvaro Lorencini. São Paulo: Editora UNESP, 1999.

CASASANTA, Mario. Dom Bosco educador. Niterói: Escolas Profissionais Salesianas, 1934.

CASOTTI, Mario S. Giovanni Bosco: il método preventivo. Brescia: La Scuola, 1940.

CASTILHO, Edson Donizetti. Carlos Leôncio da Silva: contribuições para a história da educação brasileira. Revista de Ciências da Educação, Americana, ano 9, n. 16, p. 149212, 2007.

CAVIGLIA, Alberto. Dom Bosco: uma visão histórica. São Paulo: Editora Salesiana Dom Bosco, 1987.

CERIA, Eugenio. Memorie biografiche di San Giovanni Bosco: 1886-1888. Torino:

Società Editrice Internazionale, 1937. v. 18.

CERRUTI, Francesco. Storia della pedagogia in Italia dalle origini a' tempi nostri. Torino: Tipografia e Libreria Salesiana, 1883.

CIMATTI, Vincenzo. Dom Bosco educador: contribuição para a história do pensamento e das instituições pedagógicas. Tradução de Luiz Marcigaglia. São Paulo: Escolas Profissionais Salesianas, 1939.

COLLI, Carlo. Pedagogia spirituale di Don Bosco e spirito salesiano: abbozzo di sintesi. Roma: LAS, 1982. 
CORALLO, Gino. II método educativo salesiano: I'eredità di Don Bosco. Catania: Tipografia Scuola Salesiana del Libro, 1979.

DAMAS, Luiz Antonio Hunold de Oliveira Damas. A preventividade na educação salesiana: do carisma à institucionalização. Brasília: Universa, 2004.

D’ARCAIS, Giuseppe Flores. Studi pedagogici. Padova: Editoria Liviana, 1951.

ESTRELA, Carlos. Metodologia científica. 3. ed. Porto Alegre: Artes Médicas, 2018.

FASCIE, Bartolomeo. Del metodo educativo di Don Bosco: fonti e commenti. Torino: SEl, 1927.

FERREIRA, Antônio da Silva. Prefácio. In: PAVANI, João Roberto. Princípios pedagógicos do sistema preventivo de Dom Bosco vistos através da Carta de Roma. São Paulo: Palavra \& Prece, 2013. p. 11.

FERREIRA, Antônio da Silva. Não basta amar...: a pedagogia de Dom Bosco em seus escritos. São Paulo: Editora Salesiana, 2008.

FIERRO TORRES, Rodolfo. El sistema educativo de D. Bosco em las pedagogias general y especiales. Madrid: SEI, 1953.

JAEGER, Werner. Paidéia: a formação do homem grego. São Paulo: Martins Fontes, 1995.

JUPIASSU, Hilton; MARCONDES, Danilo. Dicionário básico de filosofia. 3. ed. Rio de Janeiro: Zahar, 1996.

LENTI, Arthur J. Dom Bosco: história e carismaTradução de José Antenor Velho. Brasília: Editora Dom Bosco, 2012. (Origem: dos Becchi a Valdocco, v. 1).

LENTI, Arthur J. Dom Bosco: história e carisma. Tradução de José Antenor Velho. Brasília: Editora Dom Bosco, 2013. (Expansão de Valdocco a Roma, v. 2).

MANACORDA, Mario Alighiero. História da educação: da antiguidade aos nossos dias. Tradução de Gaetano Lo Monaco. 13. ed. São Paulo: Cortez, 2010.

MAZZOTTI, Tarso Bonilha. Estatuto de cientificidade da Pedagogia. In: PIMENTA, Selma Garrido (Org.). Pedagogia, ciência da educação? São Paulo: Cortez, 1996. p. 13-36.

MODESTI, João. Uma pedagogia perene: filosofia da educação em Dom Bosco. São Paulo: Editorial Dom Bosco, 1975. 
NANNI, Carlo. Il sistema preventivo e l'educazione dei giovani. Roma: Libreria Ateneo Salesiano, 1989.

POURTOIS, Jean-Pierre; DESMET, Huguette. A educação pós-moderna. São Paulo: Edições Loyola, 1999.

PRELLEZO, José Manuel. Educar con Don Bosco: ensayos de pedagogia salesiana. Madrid: Editorial CCS, 1997.

PRELLEZO, José Manuel. Francesco Cerruti direttore generale delle scuole e della stampa salesiana (1885-1917). Ricerche Storiche Salesiane, Gennaio-giugno, Roma, ano 5, n. 1, p. 127-164, 1986.

RICALDONE, Pietro. D. Bosco educatore. Torino: LDC, 1953.

SANDRINI, Marcos. Dom Bosco e os jovens: um binômio inseparável. Porto Alegre: [s.n.], 2012.

SANTOS, Manoel Isaú Souza Ponciano dos. Luz e sombras: internatos no Brasil. São Paulo: Salesianas, 2000.

SCARAMUSSA, Tarcísio. O sistema preventivo de Dom Bosco: um estilo de educação. São Paulo: Editora Salesiana Dom Bosco, 1984.

SCARAMUSSA, Tarcísio. Atualidade e repensamento do Sistema Preventivo de Dom Bosco. Revista de Ciências da Educação, Americana, ano 15, n. 28, p. 157-181, jan./jun. 2013.

STRECK, Danilo; REDIN, Euclides; ZITKOSKI, Jaime José (Orgs.). Dicionário Paulo Freire. 3. ed. Belo Horizonte: Autêntica, 2017.

SILVA, Carlos Leôncio da. Pedagogia: manual teórico-prático para uso dos educadores. São Paulo: Livraria Salesiana Editora, 1938. v. 1.

SOFFNER, Renato Kraide; SANDRINI, Marcos. A pedagogia e a práxis educativa de João Bosco. Revista de Ciências da Educação, Americana, ano 14, n. 26, p. 166-84, jan./jun. 2012.

STELLA, Pietro. Juan Bosco en la história de la educación. Madrid: Editorial CCS, 1996.

VECCHI, Juan E.; PRELLEZO, José Manuel. Prassi educativa pastorale e scienze dell'educazione. Roma: Editrice SDB, 1988. 


\section{Sobre os autores:}

Jorge Luís Mialhe: Pós-doutor na Université de Paris III (Sorbonne-Nouvelle), com bolsa da FAPESP e no Centre de Recherches Interdisciplinaires en Droit de I'Environnement, de l'Aménagement et de l'Urbanisme (CRIDEAU) da Université de Limoges, com bolsa da CAPES. Doutor em História Social pela Faculdade de Filosofia, Letras e Ciências Humanas da Universidade de São Paulo (FFLCH-USP). Mestre em Direito Internacional pela Faculdade de Direito da Universidade de São Paulo (FD-USP). Graduado em Direito pela USP e em História pela USP. Atualmente é professor doutor do Departamento de Educação da Universidade Estadual Paulista (UNESP), campus de Rio Claro - SP. E-mail: profmialhe@hotmail.com, Orcid: https://orcid.org/0000-0002-0744-796X

Renato Kraide Soffner: Pós-doutor pelo MIT - Massachusetts Institute of Technology (na área de Tecnologia Educacional) e no CTI Renato Archer do MCTI (na área de Gestão do Conhecimento). Doutor em Educação (Tecnologia Educacional) pela UNICAMP. Mestre em Máquinas pela USP. Especialista em Ciência da Computação pela Escola de Engenharia da Fundação Municipal de Ensino de Piracicaba. Graduado em Engenharia Agronômica pela USP, em Pedagogia pelo UNISAL e graduando em Análise e Desenvolvimento de Sistemas pelo Centro Universitário Claretiano. Atualmente é coordenador do Programa de Pós-Graduação em Educação do UNISAL e professor III da FATEC (Centro Estadual de Educação Tecnológica Paula Souza). E-mail: renato.soffner@unisal.br, Orcid: https://orcid.org/0000-0002-3174-8674

\section{Recebido em: 24/09/2020}

Aprovado em: 11/05/2021 